Pediat. Res. 5: 77-82 (1971)

Adenine

hypoxanthine-guanine

phosphoribosyltransferase
Lesch-Nyhan syndrome mental retardation purine metabolism

\title{
Adenine Therapy for Lesch-Nyhan Syndrome
}

\author{
Joseph 1). Sahuiman, Martin I. Gireene ${ }^{124]}$, Wilfred Y. Fujmoto ${ }^{[24]}$, and J. Edwin Seegmiller ${ }^{[25]}$ \\ Section on Hunan Biochenical Geneties, National Institute of . Arthritis and Metabolic Diseases, National \\ Institutes of Health, Bethesda, Maryland, US.I
}

\section{Extract}

$A$ child with the Lesch-Nyhan syndrome was identified at birth by demonstrating a gross deficiency of the enzyme hypoxanthine-guanine phosphoribosyltransferase (HPRT) in cord blood. 'Therapy with adenine, begun during the 1 st month of life, failed to prevent the development of the severe neurological damage characteristic of this discase.

\section{Sperculation}

Since this work was completed, 1)r. (irant Bartlett of San 1)iego has found (unpublished work) a very poor uptake of intravenously administered adenine- ${ }^{14} \mathrm{C}:$ in the brain of rabbits. 'This raises a possible reason for the failure of adenine to prevent the neurological dysfunction in this disease. A purine compound that is more readily taken up by brain tissue might, therefore, offer a more reasonable approach to treatment.

\section{Introduction}

Children with the severe form of $\mathrm{X}$-linked uric aciduria, the Lesch-Nyhan syndrome, suffer from incapacitating neurological disease and have marked overproduction of uric acid [12]. Treatment of the hyperuricemia of this condition with uricostric agents or allopurinol, however, does not alter the course of the neurological discase [2, 11]. These patients have a deficiency of the enzyme hypoxanthine-guanine phosphoribosyltransferase (EC. 2.1.2.8) (HPRT) [18], which altalyzes the formation of purine nucleoticles from the free purine bases hypoxanthine and guanine in the brain and all other tissues. Both the neurological manifestations of this disorder and the aberrations of purine metabolism are thought to be conseguences of this enryme deficiency, [9, 27].

The precise mechanism whereby HPRT deficiency results in neurological dysfunction is not known. Deficiency of this enzyme could lead to insufficient production of guanosine 5'-monophosphate (( $\mathbf{M}$ - 1 ), a necessary precursor of nucleic acid synthesis, or damage could result from an excessive quantity of some precursor of purine synthesis. A deficiency of HPRT is associated with an increased amount of substrate, 5-phosphoribosylpyrophosphate (PRPP) in erythrocytes [8] and skin fibroblasts [16] from HPR'-deficient patients. Both the neurological dysfunction and the excessise purine production in these patients could be related to increased PRPP concentration. Alternatively, at metabolic by-product of the excessive purine symthesis may have a toxic effect on the developing brain, or ofher substrates involved in purine synthesis de nozo may be depleted.

several lines of evidence have suggested that the purine base, adenine, may be of benefit in treatment of pattents with Lesch-Nyhan syndrome. Megaloblastic anemia develops in a small portion of such patients, and the anemia was corrected promptly in one child when treated with adenine [19]. Demars et al. [3] have shown that additional adenine, folic acid, or both are required for optimal growth of HPRT-deficient fibroblasts in tissue culture. In mammalian tissues, adenine 
is rapidly converted to its nucleotide by adenine phosphoribosyltransferase, an enzyme present in normal or increased quantities in patients with the Lesch-Nyhan syndrome [8]. 5-Phosphoribosylpyrophosphate is also utilized in this conversion. The nucleoticle adenosine 5'-monophosphate (AMP) can then be converted to GMP and other purine nucleotides (Fig. l).

We report here the results of adenine therapy in two patients with virtually complete HPRT deficiency. In one of these patients, adenine administration began in the 3rd week of life, when he was clinically normal $[20]$.

\section{Case Histories}

\section{Case 1}

$L V T$ (NIH no. 07-99-83) was the 7-1b 7-oz product of an uncomplicated term pregnancy and delivery in a 24-year-old gravida II, para I Caucasian of German descent. He was normally active and fed well without excessive regurgitation in the immediate newborn period. An older brother was normal. Although a maternal first cousin was known to be afflicted with Lesch-Nyhan syndrome, the patient's mother had declined the opportunity for prenatal evaluation of her infant by means of cultured amniotic fluid cells $[3,6$, 26].

Because of the maternal family history, blood was obtained from the umbilical cord at birth and showed no detectable HPRT activity either by a screening assay [5] or in the conventional quantitative assay [18]. In addition. a urine sample collected when the patient was 14 days old showed a markedly elevated uric acid-to-creatinine ratio [11] of 6.0 .

At 13 days of age the patient was admitted to the National Institutes of Health. His head circumference was $34.5 \mathrm{~cm}$, and general physicil and ncurological examinations were

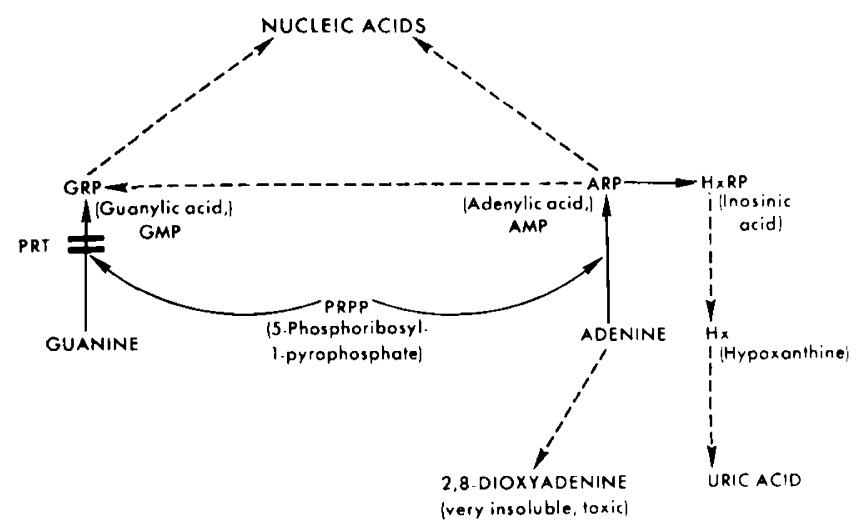

Fig. 1. Pathways available for adenine metabolism in mammalian tissues. Broken lines indicate multiple reaction sequences. and all intermediates are not included. The site of the metabolic block in pattents with the Lesch-Nyhan syndrome and deficiencs of the ensme HPRT is indicated by the heavy double line.
Table I. Initial laboratory values for patient $L V T$

Blood :
Hemoglobin

Red blood cells

Hematocrit

Platelets

Reticulocytes

White blood cells differential $(\%)$ :

Neutrophiles

Bands

l.ymphocytes

Monocytes

Basophiles

Mean corpuscular volume

Mean corpuscular hemoglobin

Mean corpuscular hemoglobin concentration

Urine :

Specific gravity

$\mathrm{pH}$

Protein

Sugar

Acetone

White blood cells/high power field

Slight amorphous sediment including urate crystals

Cerebrospinal fluid:

8 white blood cells $/ \mathrm{mm}^{3}$ (7 lymphocytes)

6 red blood cells/mut

Glucose

Protein

Chemical values in blood:

1. Blood urea nitrogen

2. Glucose

3. Phosphate

4. Uric acid

5. Creatinine

6. $\mathrm{CCO}_{2}$

7. $\mathrm{Na}$

8. $\mathrm{K}$

9. Cl

10. Calcium
$15.2 \mathrm{~g} / 100 \mathrm{ml}$ $4.4 \times 10^{8} / \mathrm{mm}^{3}$ $43 \%$ $372,000 / \mathrm{mm}^{3}$

$0.5 \%$

$8,500 / \mathrm{mm}^{3}$

40
6
44
9
1
98
34.6
35.3

1.004
5.0
negative
negative
negative
1--5

$56 \mathrm{mg} / 100 \mathrm{ml}$ $62 \mathrm{mg} / 100 \mathrm{ml}$

$9 \mathrm{mg} / 100 \mathrm{ml}$ $88 \mathrm{mg} / 100 \mathrm{ml}$ $7.8 \mathrm{mg} / 100 \mathrm{ml}$ $8.7 \mathrm{mg} / 100 \mathrm{ml}$ $0.7 \mathrm{mg} / 100 \mathrm{ml}$ $140 \mathrm{mEq} /$ liter $3.7 \mathrm{mEq} /$ liter $106 \mathrm{mEq} /$ liter $5.15 \mathrm{mEq} / \mathrm{liter}$ $19 \mathrm{mEq} /$ liter

entirely normal. Initial laboratory data, also normal except for the high levels of urate in serum, are shown in Table $I$. Electrocardiogram, electroencephalograms, and skull roentgenograms were unremarkable. No evidence of megaloblastic changes was found in a bone marrow aspirate.

When the patient was 23 days old he received oral adenine theripy in divided doses every $4 \mathrm{hr}$. Toxicity was monitored by determining blood counts, blood urea nitrogen, creatinine and uric acid levels in serum, and urinalysis three times weekly. Urinary secliment was examined daily for the presence of the toxic metabolite of adenine, 2,8dioxyadenine, as described below. The dosage was gradually increased from initial doses of $1.6 \mathrm{mg} / \mathrm{kg} / 2-4 \mathrm{hr}$ until evidence of toxicity was detected. Despite a high fluid intake, 
azotemia, increasing urate levels in serum, and increasing presence of 2,8-dioxyadenine in the urine occurred at an adenine dose of $75 \mathrm{mg} / \mathrm{kg} / 24 \mathrm{hr}$. At this point, allopurinol, $10 \mathrm{mg} / \mathrm{kg} / 24 \mathrm{hr}$, administration was begun and adenine was discontinued for 3 days. The azotemia disappeared within 1 day after adenine discontinuation and did not recur when adenine was resumed at a dose of $25 \mathrm{mg} / \mathrm{kg} / 24$ $\mathrm{hr}$ and gradually increased to $60 \mathrm{mg} / \mathrm{kg} / 24 \mathrm{hr}$. The patient was discharged from the hospital at 4 months of age and continued taking allopurinol $10 \mathrm{mg} / \mathrm{kg} / 24 \mathrm{hr}$ and adenine $60 \mathrm{mg} / \mathrm{kg} / 24 \mathrm{hr}$ at home.

By 8 months of age, despite this therapeutic regimen, the patient did not appear to be developing normally. He was unable to roll from back to front and could sustain his head in the upright position for only brief intervals. He did not laugh and did not transfer objects from hand to hand. His head circumference was $41 \mathrm{~cm}$ (less than $3 \mathrm{rd}$ percentile). He was unable to support his head when he was raised to a sitting position and was able to maintain the sitting position only with difficulty even when supported. Hyperextension and pronation of the arms were present during feeding. The direct tendon reflexes in the legs were hyperactive, and unsustained clonus was present at both ankles. His tongue had a fresh raw notch $0.5 \mathrm{~cm}$ wide and approximately as deep at the tip; this had apparently been chiselled out by the action of his only teeth, the two lower central incisors.

At 10 months of age the patient had progressed little from his developmental level at 8 months. Clear-cut evidence of spasticity was present. No additional self-mutilation was noted.

\section{Case 2}

SM (NIH no. 07-60-55). This 13-ycar-old, 26-kg Negro male had all the clinical and biochemical manifestations of the Lesch-Nyhan syndrome, including undetectable HPRT activity in his erythrocytes and a urinary uric acid-to-creatinine ratio of 4.4 . He had scars and deformities of the fingers from biting, but he was unusual in that his lips and tongue showed no lesions. No change in the patient's clinical state was noted during his therapy with progressively increasing doses of adenine over a 20-day period; he continued to show spasticity, athetoid movements, and selfmutilating behavior. At an adenine dose of $35 \mathrm{mg} / \mathrm{kg} / 24 \mathrm{hr}$ the patient developed a decline in urine output, marked crystalluria, and dysuria. He also showed evidence of in. creased excretion of 2,8-dioxyadeninc in his urine. Administration of adenine was decreased and allopurinol begun; there followed a rapid reversal of these evidences of toxicity (Figure 2).

\section{Special Studies}

\section{Animal Studies of Adenine Nephrotoxicity}

Adenine is oxidized by the enzyme xanthine oxidase to 2,8-dioxyadenine, an exceedingly insoluble purine

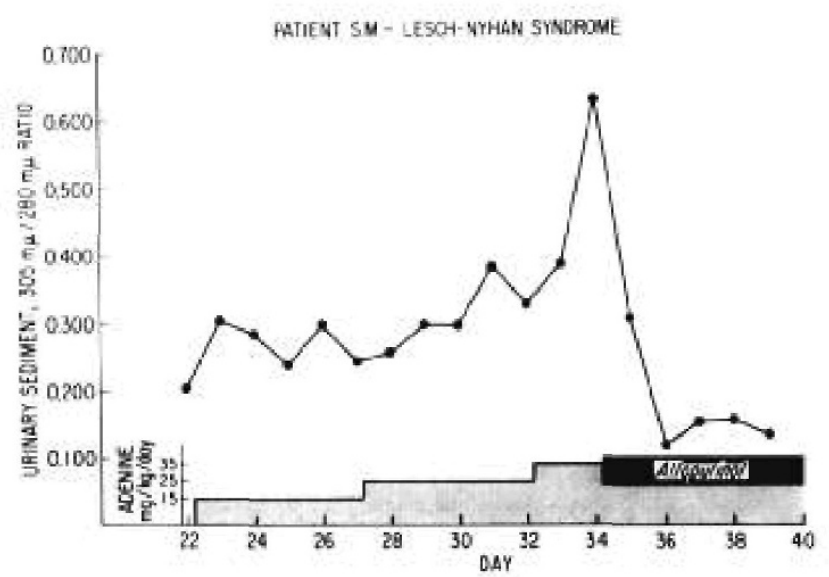

Fig. 2. Urinary dioxyadenine content, measured by ratio of absorbances of solution of urinary sediment at $305 \mathrm{~m} \mu / 280 \mathrm{~m} \mu$, plotted against dose of adenine in patient SM. See text for details of measurements of ratio. The sharp rise in the ratio at the highest dose of adenine was taken as evidence of toxicity.

Table II. Effect in rats of allopurinol on renal toxicity of adenine

\begin{tabular}{lrrcl}
\hline Group & $\begin{array}{c}\text { Adenine } \\
\text { dosage, } \mathrm{mg} / \mathrm{kg}\end{array}$ & $\begin{array}{c}\text { No. of } \\
\text { rats }\end{array}$ & $\begin{array}{c}\text { Mean kidney } \\
\text { weight, } \mathrm{g} / \mathrm{rat}\end{array}$ & \multicolumn{1}{c}{ Crystals, 1-t+ } \\
\hline$A_{1}$ & 70 & 3 & 1.78 & $0,3+, 1+$ \\
$A_{2}$ & 250 & 3 & 1.81 & $3+, 4+, 3+$ \\
$B_{1}$ & 70 & 3 & 1.44 & $0,0,0$ \\
$B_{2}$ & 250 & 3 & 1.90 & $3+, 2+, 2+$ \\
$C$ & 0 & 3 & 1.47 & $0,0,0$
\end{tabular}

${ }^{1}$ Groups $A_{1}$ and $A_{2}$ received adenine only. Groups $B_{1}$ and $B_{2}$ were pretreated with allopurinol and then received adenine. Group $C$ was used as a control. See text for details of study.

compound [1]. Renal failure accompanying the precipitation of dioxyadenine crystals in renal tubules is the principal toxic effect observed in animals after adenine administration [15]. Since allopurinol, a potent inhibitor of xanthine oxidase, would be expected to prevent the oxidation of adenine to its toxic metabolite, we undertook a limited study to test whether allopurinol would protect against adenine toxicity.

Male rats of the Sprague-Dawley strain, $200-300 \mathrm{~g}$, kept in the fed state, received adenine [21] in aqueous suspension by gastric intubation in a single dose (groups $A-1$ and $A-2$ ). Other animals (groups $B-1$ and $B-2)$ were pretreated with three doses of allopurinol $(10 \mathrm{mg} / \mathrm{kg} /$ dose) at $12-\mathrm{hr}$ intervals, and the adenine was administered $2 \mathrm{hr}$ after the last dose of allopurinol. An untreated group (group $C$ ) was used as a control. All animals were killed $24 \mathrm{hr}$ after adenine administration. The kidneys were removed and weighed, and unstained coded sections were examined under the polarizing microscope for the birefringent crystals 


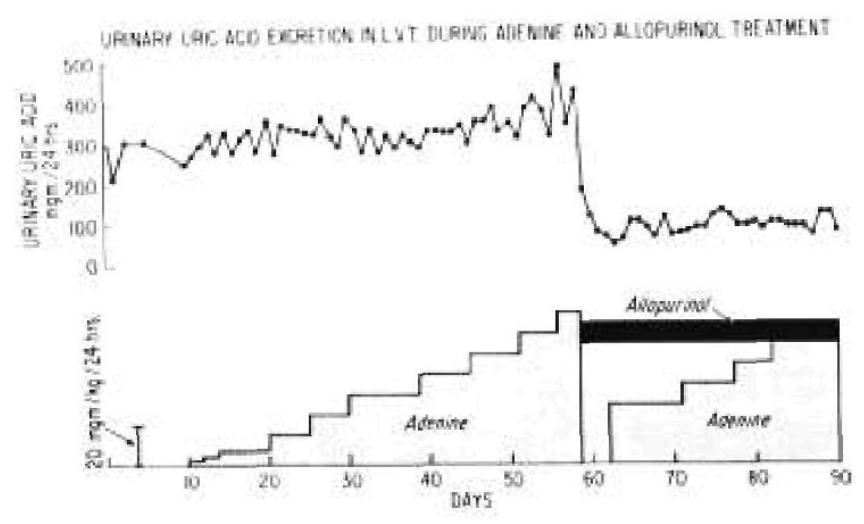

Fig. 3. Urinary uric acid excretion in patient I.I'T during treatment with adenine and allopurinol. Allopurinol, $10 \mathrm{mg} / \mathrm{kg} /$ $24 \mathrm{hr}$, was started when signs of adenine nephrotoxicity appeared.

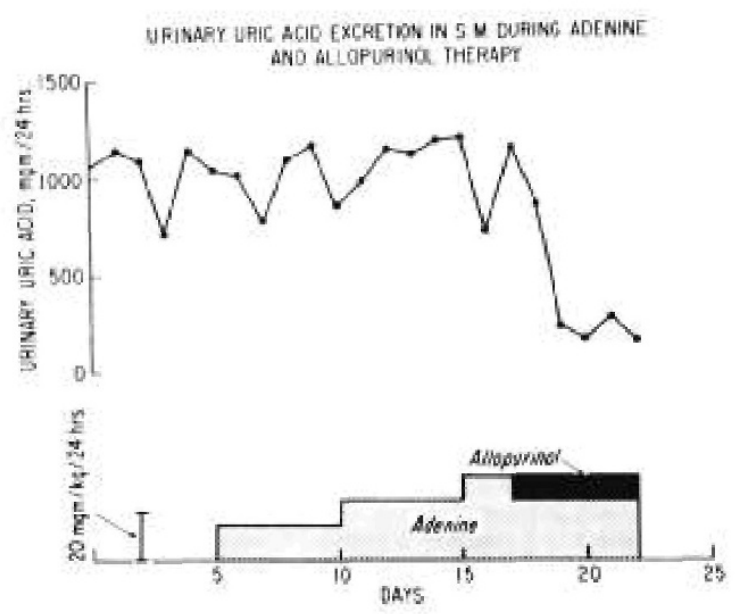

Fig. f. Urinary uric acid excretion in patient $S M$ during treatment with adenine and allopurinol. Allopurinol. $16 \mathrm{mg} \mathrm{kg} / 2.4 \mathrm{hr}$, was started when signs of adenine nephrotoxicity appeared.

typical of dioxyadenine. 'The observer was unaware of the code used, and slides were graded in random order. Results are summarized in Table Il. The data suggest that at the lowest dose of adenine, $70 \mathrm{mg} / \mathrm{kg}$ (group B-1), allopurinol had a significant protective effect against adenine nephrotoxicity. The kidneys of this group of rats did not exhilbit the pale, swollen appearance of "adenine kidneys" $[15]$ and had no detectable crystal deposition. At extremely high adenine doses, however, allopurinol in the amount used did not protect against adenine toxicity.

\section{Urinary Dioxyadenine in l'atients during Adenine Therapy}

Dioxyadenine has a strong ultraviolet absorption at $305 \mathrm{~m} \mu$, whereas uric acid and other naturally occur- ring urinary purines absorl) maximally at wave lengths less than $290 \mathrm{~m} \mu$ in acidlic solutions. The high ratio of absombance at $305 \mathrm{~m} 11 \mu$ (o alssorbance at $280 \mathrm{~m} \mu$ has been used as an indication of the content of dioxyadenine in body fluids [15].

I'en-milliliter aliquots of freshly voided morning urine samples from each patient were centrifuged, the supernatant was decanted, and the sediment was dissolved in $5 \mathrm{ml}$ of $1 \mathrm{~N}$ HCl. Residual insoluble material was removed by centrifugation, and the ratio of absorption at $305 \mathrm{~m}_{\mu}$ to that at $280 \mathrm{~m}_{\mu}$ was determined on a suitable dilution of the supernate with a spectrophotometer [22]. As shown in Figure 2, the $305 \mathrm{~m}_{\mu}$-to$280 \mathrm{~m} \mu$ ratio increased with increasing doses of atlenine. In both patients, a sharp increase in this ratio was noted when adenine toxicity occurred.

\section{Urinary Uric Acid Excretion}

'Iwenty-four-hour urine was collected on ice using $3 \mathrm{ml}$ of toluene as preservative. The urine was alkalinised with lithium carbonate and heated to redissolve any precipitated uric acid, and uric acid was then analyzed by a specific enzymatic method [13]. Patients received purinc-free diets during all study periods.

Adenine administration resulted in no significant change in total uric acid excretion in the urine in either patient (Figs. 3 and 4). A small increase in uric acid excretion in $I . J \%$ at the highest adenine dose may have reflected conversion of adenine to uric acid; in previous studies, it was found that $15-25 \%$ of a single oral close of $1.0 \mathrm{~g}$ adenine-1:3 $\mathrm{C}$ given to normal adults was converted to uric acid [17]. Similar information during chronic administration of adenine is not available. Since specialized studies were not performed to ascertain the fraction of the administered adenine that was comverted to urate in the patients in this study, the effect of adenine on the patients' endogenous production of uric acid could not be directly measured.

\section{Erythrocyte PRPP Me'asurements}

Patients with HPRT deficiency have a markedly increased concentration of PRPP in erythrocytes [8], presumably reflecting decreased utilization of this substrate in the reaction catalyzed by the missing HPRT ensyme (Fig. 1). I lifferent enzyme which also utilizes PRPP as a substrate, adenine phosphoribosyltransferase, is present in nomal or increased amounts in these ervthrocrtes [7].

Heparinized venous bleod was chilled and centrifuged at $800 \times g$ for $10 \mathrm{~min}$, plasma and buffy coat 
were removed, and the red cells were washed twice with Krebs-Ringer buffer, $\mathrm{pH} 7.1$, at $1^{\circ}$. A $2 \%$ suspension of the washed erythrocytes was then assayed for PRPP content by a modification [8] of the method of Henderson and Khoo [10]. Prior to adenine treatment, erythrocyte PRPP concentrations were elevated far above normal in both patients (Figs. 5 and 6). Oral adenine administration resulted in striking reductions of the erythocyte PRPP in these subjects.

\section{Discussion}

The presence of a lag in development, and such findings as hyperreflexia, posturing of the hands, and biting of the tongue strongly suggest that therapy with high closes of adenine failed to prevent the development of neurological dysfuction in patient $L V T$, even though treatment was started in the lst month of life. Similarly, the drug had no effect on the well established neurological deficits in patient $S M$. The decrease in erythrocyte PRPP levels with adenine administration demonstrates that adenine was absorbed from the gastrointestinal tract in our patients. There is, however. considerable possibility that only a small amount of the administered adenine entered the central nervous system of these patients. In experimental animals, adenine-1' $C$ enters the brain to a very limited degree [4]. Furthermore, the uptake of adenine by the brain cloes not increase linearly with adenine dose. Such factors could explatin the failure of adenine to prevent development of neurological dysfunction.

Administration of adenine-1" (: resulted in at substantial inhibition of purine synthesis de nowo in both nomal and gouty sulsjects, including a patient with an incomplete deficiency of HPRT, without diminishing total uric acid excretion in the urine [17]. Likewise. uric acid excretion in urine did not change despite increasing doses of adenine in our two patients; a similar observation has been made by Berman et al. [2]. If it is assumed that a significant proportion of the administered adenine was converted to uric acid and excreted, it may be infered that adenine administration also caused a reduction in enclogenous uric acid production in these patients. The magnitude of this clfect, however, is evidenty small enough that adenine cannot be recommenced as useful for reducing the hyperuricemia or hyperuricosuria seen in patients with Lesch-Nyhan syndrome.

Adenine therapy did surceed in corresting one alsnormal biochemical variable, for the elevated levels of PRPP in erythocytes fell toward the normat range. Since PRPP concentrations in brain, liver, and other

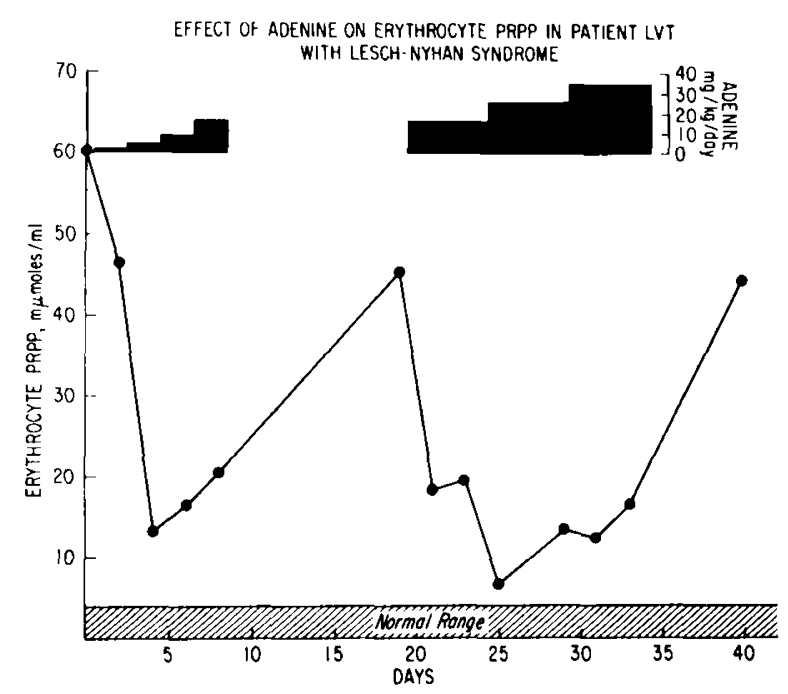

Fig. 5. Effect of adenine on erythrocyte 5-phosphoribosyl-1pyrophosphite in patient IVT. Normal range was determined from values from 10 normal adults.

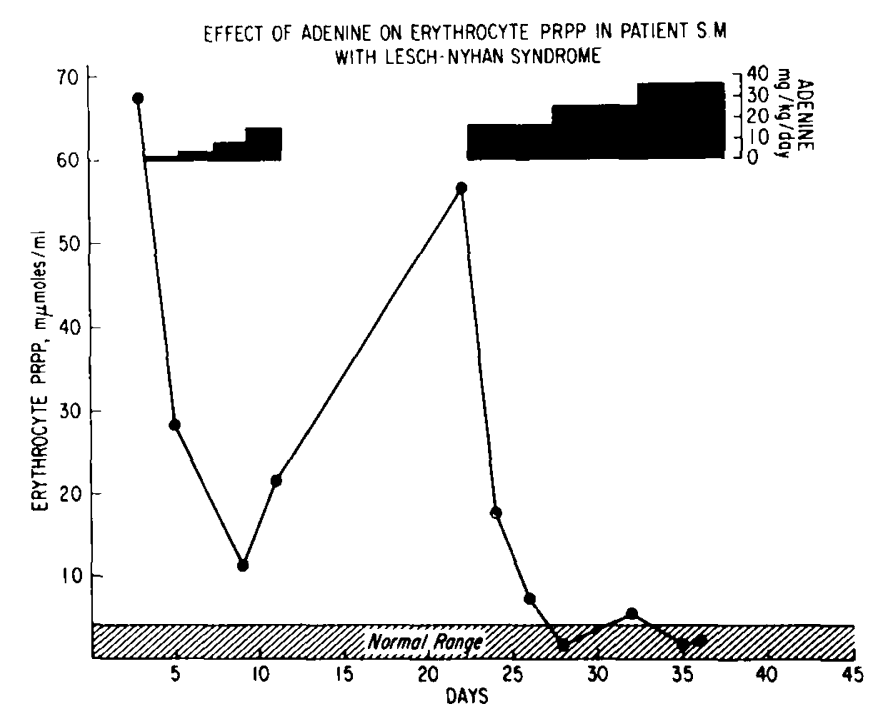

Fig. o. Effect of adenine on erythrocyte s-phosphoribosyl-1pyrophosphate in patient SM. Normal range was determined from values for 10 normal adults.

metabolically active tissues possessing intact purine biosynthetic pathways de nozo could not be directly measured, the importance of this compound in explaining the accelerated purine synthesis in HPRT-deficient pattients could not be determined. The possibilities therefore remain that in these metabolically active tisstes PRPP has a very high synthesis and turnover rate, that IIPR'T deficiency markedly reduces PRPP degradation and results in its accumulation, and that the amount of adenine administered was insufficient to correct the PRPP abnomalities in these target organs. 


\section{Summary}

Oral therapy with adenine, begun in the 1st month of life, did not prevent the development of neurological dysfunction by 8 months of age in a child with deficiency of HPRT (Lesch-Nyhan syndrome), and similar treatment had no effect on an older child with the same disorder. Uric acid excretion in the urine did not decrease during adenine therapy; however, there was a dramatic decline in elevated erythrocyte PRPP concentrations during treatment. The absorbance ratio at $305 / 280 \mathrm{~m}_{\mu}$ of dissolved urinary sediment was found useful for monitoring the nephrotoxicity which appeared after administration of high doses of adenine. This toxicity was minimized by simultaneous therapy with allopurinol, which inhibits the conversion of adenine to the less soluble derivative, 2,8-dioxyadenine, the substance responsible for nephrotoxicity.

\section{References and Notes}

1. Bronich, A., Brown, G. B., Phitips, F. S., and Tulersch, J. B.: Dired oxidation of adenine in rivo. J. Biol. Chem., 183: 267 $(1950)$.

2. BFRMAN, P. H., Bar.s, M. F., MND DAnCis, J.: Congenital hyperuricemia, an inborn error of purine metabolism associated with psychomotor retardation, athetosis, and selfmutilation. Arch. Neurol., 20: it (1969).

3. IfMars, R., SARTo, G., Felix, J. S., ANd Benkf, P.: LeschNyhan mutation: Prenatal detection with amniotic fluid cells. Science, 16t: 1303 (1969).

4. ForD, D. H., AND RHINIs, R.: $\mathrm{H}^{3}$ accumulation in spinal cord Heurons following intravenous injection of adenine- $\mathrm{I}^{3}$ as determined by liquid scintillation counting procedures on dissected neurons. Acta Neurol. Scand., 13: 127 (1967).

5. Fujmoto, W. Y., (iretenf, M. L.. and Sefgimiter, J. E.: Xlinked uric aciduria with neurological disease and self mutilation: Diagnostic test for the enzyme defect. J. Pediat., 73: $920(1968)$

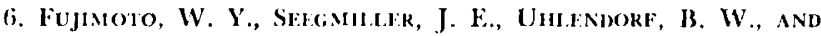
Jacomson, C. B.: Biochemical diagnosis of an X-linked disease in utero. Iancet, ii: 511 (1968).

7. Grfinf, M. L.., Boyte, J. A., Ann Sfrcimilter, J. E.: Substrate stabilization: Mechanism for elevated adenine phosphoribn. syltransferase activity in crythrocytes lacking hypoxanthincguanine phosphoribosylt ransferase. Science, 167: 887 (1970).

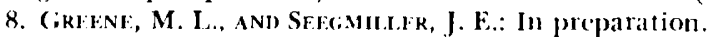

9. Hrvofrson, J. F.: Possible functions of hypoxanthine guanine phosphoribosyltransferase and their selation to the biochemical pathology of the Icesch-Nyan sundrome, Fed. Proc., 27: 1075 (1968).

16. Mrntroson, J. F., AND KHoO, M. K. Y.: Synthesis of 5-phos- phoribosyl-1-pyrophosphate from glucose in Ehrlich ascites tumor cells in vitro. J. Biol. Chem., 2.40: 2349 (1965).

11. Khufman, J. M., Greent, M. I.., and Seegmuller, J. F.: Urine uric acid to creatinine ratio- $A$ screening test for inherited disorders of purine metabolism. J. Pediat., 73: 583 (1968).

12. Iescit, M., Ann Nrina , W. I.. A familial disorder of uric acid metabolism and central nervous system function. Amer. J. Mcel., 36: 561 (I96:1).

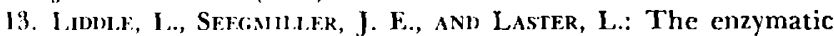
spectrophotometric method for determination of uric acid. J. Iab. Cilin. Med., 54: 903 (1959).

14. Marks, J. F., Baum, J., Keele, D. K., Kay, J. L., and MacFARIIN, A.: Iesch-Nyhan syndrome treated from the early neonatal period. Pediatrics, 42: 357 (1968).

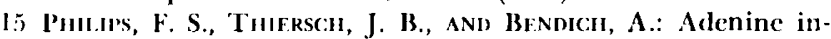
toxication in relation to in vizo formation and deposition of 2,8-dioxyadenine in renal tubules. J. Pharmacol., 104: 20 (1959).

16. Rosenbloom, F. M., Henderson, J. F., Caidwell, I. C., Kelly, W. N., AnD SFfcimit.t.er, J. E.: Biochemical bases of accelerated purine biosynthesis $d c$ novo in human fibroblasts lacking hypoxanthine-guanine phosphoribosyltransferase. J. Biol. (hom., 2ł3: 1166 (1968).

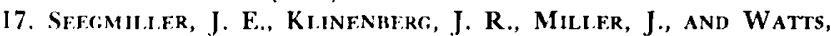
R. W. E.: Suppression of glycine ${ }^{15} \mathrm{~N}$ incorporation inso urinary uric acid by adenine $-8{ }^{13} \mathrm{C}$ in normal and gouty subjects. J. C:lin. Invest., 47: 1193 (1968).

18. Smgimltek, J. F., Rosinhloom, F. M., and Kel.ty, W. N.: Entyme defect associated with a sex-linked human neurological disorder and excessive purine synthesis. Science, 155: $1682(1967)$

19. Van dfk Zfe, S. P. M., Schrettien, F. D. A. M., ANd Monnens, I. A. H.: Megaloblastic anemia in the Iesch-Nyhan syndrome. Lancet $i$ : 1427 (1968).

20. Informed consent was obtained in accordance with the provisions set forth in the Declaration of Helsinki.

21. Schwarz Biokesearch, Orangeburg, N. Y.

22. Model 1)U, Beckman Instruments, Fullerton, Calif.

23. The technical assistance of Clementine $\mathbf{S}$. Sessoms is gratefully acknowledged.

24. Present address: Department of Medicine, University of Watshington, Seattle, Wash. 98105 (USA).

25. Requests for reprints should be addressed to: J. Edwin Seegmiller, M.D., Department of Medicine, University of California. San Diego, Ia Jolla, Calif. 92037 (USA).

26. Bovi., J. A., Raivio, K. O., Astrin, K. H., Schulman, J. D.,

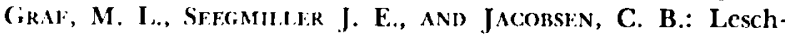
Nyhan syndrome: Preventive control by prenatal diagnosis. Science, 169: 688 (1970).

27. Rosinbloon, F. M., Kiltiey, W. N., Mitler, J., Henderson, J. F., AND Stronitike, J. F.: Inherited disorder of purine motabolism: Correlation between central nervous system dysfunction and biochemical defects. J. Amer. Med. Ass., 202: $175(1967)$.

28. Accepted for publication December 10, 1969. 